\title{
PRODUÇÃO DE BANANAS-PASSA COM FRUTOS DE VARIEDADES MELHORADAS E AVALIAÇÃO DA QUALIDADE FÍSICO-QUÍMICA E SENSORIAL
}

\author{
ELISETH DE SOUZA VIANA \\ RONIELLI CARDOSO REIS \\ LUISE DE OLIVEIRA SENA \\ MIGUEL BURY DOS SANTOS JÚNIOR \\ PAULA NUNES RIBEIRO DA SILVA
}

\begin{abstract}
A produção de passas é uma alternativa interessante para o aproveitamento da banana, uma fruta climatérica que se deteriora rapidamente. Esse estudo teve como objetivo avaliar o potencial dos frutos de variedades melhoradas de bananeira para o processamento de passas e caracterizar o produto quanto às características físicas, físico-químicas e sensoriais. Foram utilizados frutos de cinco variedades melhoradas ('BRS Caipira', 'BRS Princesa', 'BRS Preciosa', 'BRS Platina', 'BRS Vitória') e duas comerciais ('Grande Naine' e 'Prata Anã') para a produção de bananas-passa por desidratação convectiva, a $65{ }^{\circ} \mathrm{C}$, até umidade máxima de $25 \%$. Os frutos in natura e as passas foram caracterizados mediante análises físicas (tamanho, diâmetro, rendimento e cor da polpa), físico-químicas (teor de sólidos solúveis, acidez titulável, relação SS/AT, pH e umidade) e sensoriais. Após a desidratação, observouse redução de $48,52 \%$ e $13,39 \%$ no diâmetro e no comprimento dos frutos, respectivamente. O produto apresentou coloração mais escura e de tonalidade amarelo alaranjada em relação aos frutos in natura. Houve incremento do teor de sólidos solúveis de $24,38^{\circ} \mathrm{Brix}$ para $71,61^{\circ}$ Brix nas passas em relação aos frutos in natura. As passas das sete variedades formaram um único grupo considerando os teores de SS, AT, pH e relação SS/AT e apresentaram umidade inferior a $24 \%$. As passas da variedade BRS Princesa apresentaram o maior rendimento $(23,28 \%)$. As variedades melhoradas apresentaram percentuais de aprovação superiores a $65 \%$ para aparência, aroma, sabor e impressão global, e superior a $51 \%$ para cor e textura. As variedades melhoradas podem ser usadas para a produção de passas, com destaque para a BRS Preciosa.
\end{abstract}

1 Economista Doméstica, Doutora em Microbiologia Agrícola, Embrapa Mandioca e Fruticultura, Cruz das Almas-BA (eliseth.viana@embrapa.br).

2 Engenheira de Alimentos, Doutora em Ciência e Tecnologia de Alimentos, Embrapa Mandioca e Fruticultura, Cruz das Almas-BA (ronielli.reis@embrapa.br).

3 Graduanda em Engenharia Agronômica, Universidade Federal do Recôncavo da Bahia, Cruz das AlmasBA (luise-sena@hotmail.com).

4 3. Graduando em Ciências Biológicas, Universidade Federal do Recôncavo da Bahia, Cruz das Almas-BA (miguelotdb@hotmail.com). 


\section{INTRODUÇÃO}

A banana (Musa spp.) é uma das frutas mais consumidas no mundo e é produzida em quase todos os países tropicais, devido ao seu baixo preço, alto valor nutritivo (Fernandes et al. 2006) e por apresentar características sensoriais que agradam aos consumidores. A produção mundial de bananas foi de aproximadamente 106,7 milhões de toneladas, em 2013, sendo a Índia, China, Filipinas, Brasil e Equador os maiores produtores (FAO 2015).

Trata-se de uma cultura de importância expressiva para o Brasil, sendo as principais variedades cultivadas no território brasileiro pertencem aos subgrupos Cavendish ('Nanica', 'Nanicão', 'Grande Naine'), Prata ('Prata Anã' e 'Pacovan'), Maçã e Terra (CEAGESP 2006). Tais variedades são susceptíveis à Sigatoka-negra, Sigatoka-amarela e/ou mal do Panamá, doenças que podem dizimar as plantações. Como alternativa para conter o avanço de algumas doenças consideradas devastadoras para as cultivares tradicionais, pesquisadores têm indicado o plantio de variedades resistentes obtidas pela seleção dentro dos recursos genéticos existentes ou pela geração de novas cultivares (Silva et al. 2003, Amorim et al. 2011).

É importante considerar que os frutos da bananeira, independente de serem advindos de variedade comercial ou resistente, quando maduros, deterioram-se rapidamente por serem climatéricos e por apresentarem elevado teor de água na sua constituição. Assim a industrialização dos frutos é uma alternativa para aproveitamento dos frutos fora de padrão para consumo in natura e do excedente da produção, de modo a disponibilizá-los para consumo durante todo o ano (Azoubel et al. 2010, Karim et al. 2005).

Entre os processos de aproveitamento industrial, a produção de banana-passa é interessante, por tratar-se de um alimento nutritivo, conveniente e de alto valor agregado, que requer baixo investimento inicial para sua produção, quando comparado com outros métodos de conservação de frutas. A tecnologia utilizada para a produção de banana-passa promove a concentração dos nutrientes, permitindo uma maior ingestão destes por grama do produto, além de preservar a qualidade sensorial, pois o produto não passa por tratamentos drásticos de temperatura.

O mercado interno para banana-passa é promissor por tratar-se de um produto com boa aceitação sensorial, que tem apelo de produto próximo ao natural e que pode ser consumido como fruta desidratada, ou ser empregado como ingrediente em formulações de outros produtos como bolos, tortas, recheios, bombons e outros (Silva et al. 1995).

A remoção de umidade durante a desidratação das bananas provoca a diminuição da atividade de água do produto, com consequente inibição do desenvolvimento de micro-organismos e das alterações de origem físico-química, com consequente aumento de sua vida de prateleira (Cano-Chauca et al. 2004).

No Brasil houve um crescimento da oferta de frutas desidratadas em diversos estabelecimentos comerciais. No caso das passas de banana, as cultivares Nanica e a Prata são as mais utilizadas, entretanto, variedades resistentes à doenças podem ser adequadas para este processo.

Nesse contexto, esse estudo teve como objetivo avaliar o potencial dos frutos de variedades melhoradas de bananeira para o processamento de passas e caracterizar o produto obtido quanto às suas características físicas, físico-químicas e sensoriais.

\section{MATERIAL E MÉTODOS}

Os frutos utilizados para o processamento das bananas-passa foram provenientes da área experimental da Embrapa Mandioca e Fruticultura, localizada em Cruz das Almas, BA (1240'39" S e 39॰06/22» W a $226 \mathrm{~m}$ de altitude).

Foram utilizados frutos de cinco variedades melhoradas ('BRS Caipira', 'BRS Princesa', 
'BRS Preciosa', 'BRS Platina', 'BRS Vitória') e duas variedades comerciais ('Grande Naine' e 'Prata Anã'), conforme descrito na Tabela 1. Utilizou-se o delineamento inteiramente casualizado, com três repetições experimentais, sendo que cada cacho representou uma repetição. Os frutos foram colhidos no estádio 2 de maturação (casca verde com traços amarelos) e processados no estádio 7 de maturação (casca amarela com áreas marrons), segundo a escala de Von Loeseck (CEAGESP 2006).

TABELA 1- DESCRIÇÃO DOS GENÓTIPOS DE BANANEIRA AVALIADOS

\begin{tabular}{|c|c|c|c|}
\hline Genótipo & Genoma & Genealogia/porte & Resistência a doenças \\
\hline BRS Caipira & AAA & $\begin{array}{l}\text { Cultivar tipo Ibota (África Ocidental). } \\
\text { Porte: média a alta. }\end{array}$ & $\begin{array}{l}\text { Resistente à SA, SN, MP e broca } \\
\text { do rizoma; susceptível a nematoi- } \\
\text { des e Moko. }\end{array}$ \\
\hline BRS Princesa & AAAB & $\begin{array}{l}\text { Híbrido de Yanganby n.2 e M53. Porte: } \\
\text { média a alta. }\end{array}$ & $\begin{array}{l}\text { Resistente à AS, moderadamen- } \\
\text { te susceptível à SN, tolerante ao } \\
\text { mal do Panamá e susceptível ao } \\
\text { Moko. }\end{array}$ \\
\hline BRS Preciosa & AAAB & $\begin{array}{l}\text { Híbrido entre Pacovan e o diploide } \\
\text { M53. Porte: alta. }\end{array}$ & $\begin{array}{l}\text { Resistente à SA, moderadamente } \\
\text { susceptível à SN, tolerante ao MP, } \\
\text { susceptível ao Moko. }\end{array}$ \\
\hline BRS Platina & AABB & Híbrido de Prata Anã. Porte: médio & $\begin{array}{l}\text { Resistentes à SA, MP, nematoides } \\
\text { e BR, moderadamente resistente à } \\
\text { SN, susceptível ao Moko. }\end{array}$ \\
\hline BRS Vitória & AAAB & $\begin{array}{l}\text { Híbrido de Pacovan com M53. Porte: } \\
\text { alto }\end{array}$ & $\begin{array}{l}\text { Resistente à SA, SN e MP, sus- } \\
\text { ceptível ao Moko, moderadamente } \\
\text { susceptível a nematoides e BR. }\end{array}$ \\
\hline Prata-Anã & AAB & $\begin{array}{l}\text { Cultivar tradicional do tipo Prata. Porte: } \\
\text { baixo }\end{array}$ & $\begin{array}{l}\text { Suscetível à SA, SN e Moko, mo- } \\
\text { deradamente susceptível ao MP, } \\
\text { moderadamente resistente a BR. }\end{array}$ \\
\hline Grande Naine & AAA & $\begin{array}{l}\text { Cultivar tipo Cavendish. Porte: médio a } \\
\text { baixo. }\end{array}$ & $\begin{array}{l}\text { Susceptível a SN, SA, Moko e BR; } \\
\text { resistente ao MP. }\end{array}$ \\
\hline
\end{tabular}

SN- Sigatoka-negra; SA- Sigatoka-amarela; MP- mal-do-Panamá; BR- broca do rizoma.

Os frutos maduros foram devidamente lavados e sanitizados por imersão em solução clorada (50 mg L-1 de cloro residual livre) por 10 minutos e lavados em água corrente para retirada do excesso de cloro. Após essa etapa, os frutos foram descascados manualmente e o mesocarpo removido com auxílio de faca de aço inoxidável. Em seguida os frutos foram submetidos ao processo de secagem, utilizando-se secador de bandejas, à temperatura de $65^{\circ} \mathrm{C}$, com uma velocidade fixa do ar de secagem de $1,5 \mathrm{~ms}^{-1}$.

Ao longo da secagem, as bandejas foram invertidas e alternadas para a obtenção de um produto mais homogêneo. Após atingirem o peso ideal, correspondente à umidade máxima de $25 \%$ (b.u.), as bananas-passa foram mantidas no desidratador por 20 minutos para o completo resfriamento, apenas com o sistema de circulação de ar ligado. As bananas-passa foram armazenadas em sacos de polietileno de baixa densidade e armazenadas por três dias para a uniformização da umidade (etapa de condicionamento).

Os frutos das sete variedades foram avaliados in natura e após a desidratação quanto às características físicas e físico-químicas. Foram utilizados três frutos de cada variedade para as análises físicas, que incluíram as medidas de diâmetro do fruto (DF, em $\mathrm{cm}$ ), comprimento do fruto $(\mathrm{CF}, \mathrm{em} \mathrm{cm})$, cor da polpa e rendimento (\%). A cor da polpa foi avaliada utilizando-se Colorímetro 
Konica Minolta, modelo CR-400, no sistema CIELAB, iluminante D65. Foram avaliadas a coordenada $\mathrm{L}^{*}$ (luminosidade) e os valores de $\mathrm{C}^{*}$ (croma/saturação da cor) e $\mathrm{h}^{*}$ (tonalidade/ ângulo de cor). As leituras foram realizadas em dois lados opostos do fruto descascado. O rendimento foi calculado com auxílio de balança analítica e expresso em porcentagem.

A avaliação físico-química incluiu as determinações dos teores de sólidos solúveis (SS, em 'Brix), da acidez titulável (AT, em \% de ácido málico), pH, relação SS/AT (ratio) e umidade (em \%), segundo metodologia o IAL (2008).

Os testes de aceitação sensorial, intensidade de atributos e intenção de compras das bananas-passa foram realizados por 60 julgadores não treinados, seguindo-se o delineamento em blocos casualizados. As amostras foram codificadas com números aleatórios de três dígitos para avaliação dos atributos sensoriais aparência, cor, aroma, sabor, textura e aceitação global, por meio de escala hedônica estruturada de nove pontos, sendo os extremos "desgostei muitíssimo" (1) e "gostei muitíssimo" (9), conforme NBR 14141 (ABNT 1998). Para a avaliação da aparência, as bananas-passa foram colocadas inteiras em pratos descartáveis e dispostas sobre uma mesa fora da cabine de degustação. Para a avaliação dos demais atributos e realização dos demais testes, as amostras foram cortadas em pedaços de 3 centímetros e apresentadas aos consumidores em cabines individuais, sob luz branca.

O diagnóstico de atributos foi realizado utilizando-se escala de intensidade de nove pontos, para os atributos cor (muito clara/muito escura), aroma (fraco/forte), sabor de banana (fraco/forte), doçura (pouco doce/muito doce) e textura na boca (muito mole/muito dura), como descrito em Meilgaard et al. (2006).

A intenção de compra desses produtos foi avaliada, a partir de uma escala de cinco pontos, sendo os extremos os termos "certamente compraria" (5) e "certamente não compraria" (1).

Os dados das características físicas, físico-químicas e do teste de aceitação sensorial dos frutos foram submetidos à análise de variância e as médias foram comparadas pelo teste de SkottKnott a 5\% de probabilidade, com auxílio do Programa SISVAR (Ferreira 2010).

As porcentagens de aprovação dos atributos sensoriais foram calculados com base nas notas iguais ou superiores a 6 . Os dados do teste de intenção de compras foram apresentados por meio da soma das porcentagens dos termos "provavelmente compraria" e "certamente compraria".

\section{RESULTADOS E DISCUSSÃO}

\section{AVALIAÇÃO FÍSICA E FÍSICO-QUÍMICA}

As variedades avaliadas tanto in natura quanto desidratadas formaram um único grupo para a característica diâmetro do fruto (Tabelas 2 e 3). As variedades Grande Naine, BRS Platina, BRS Preciosa e BRS Vitória tanto in natura quanto desidratadas ficaram no mesmo grupo e apresentaram os maiores comprimentos de fruto (Tabelas 2 e 3). Verificou-se que o processo de desidratação ocasionou redução média de $48,52 \%$ e 13,39\% no diâmetro e no comprimento dos frutos, respectivamente (Tabelas 2 e 3 ).

O comprimento e o diâmetro dos frutos in natura são características importantes, pois interferem no tempo de secagem das bananas-passa, no custo de produção devido à demanda energética. $O$ tamanho das bananas-passa determina ainda o tamanho da embalagem a ser utilizada pelas agroindústrias. Jesus et al. (2005) obtiveram redução de cerca de $30 \%$ no diâmetro e de $8 \%$ a $15 \%$ no comprimento de bananas-passa obtidas por desidratação osmótica a partir de nove genótipos de bananeira. Ainda no mesmo estudo, esses autores obtiveram medidas de comprimento do produto que variaram de $8,02 \mathrm{~cm}$ ('BRS Caipira') a 13,08 cm ('Prata Graúda').

Com relação à cor da polpa, a coordenada $L^{*}$ que se refere à luminosidade e representa o quanto a cor de um produto é mais ou menos clara, observou-se que a variedade Grande 
Naine, destacou-se por apresentar cor mais escura tanto na sua forma in natura $(77,40)$ quanto na desidratada $(32,32)$, apresentando menores valores $L^{*}$ (Tabelas 2 e 3 ). A polpa dos frutos in natura dessa variedade apresentou ainda coloração mais intensa $\left(C^{*}=32,73\right)$ e mais amarelada $\left(h^{*}=88,87^{\circ}\right)$ em relação às demais variedades (Tabela 2$)$.

TABELA 2. MÉDIAS DAS CARACTERÍSTICAS FÍSICAS E FÍSICO-QUÍMICAS DE FRUTOS IN NATURA DE VARIEDADES DE BANANEIRA. CRUZ DAS ALMAS, BA, 2015.

\begin{tabular}{lcccccccccc}
\hline Variedade & DF & CF & L* $^{*}$ & $\mathrm{C}^{*}$ & $\mathrm{~h}^{*}$ & $\mathrm{SS}$ & $\mathrm{AT}$ & $\mathrm{SS} / \mathrm{AT}$ & $\mathrm{pH}$ & Umidade \\
\hline BRS Caipira & $3,11 \mathrm{a}$ & $10,82 \mathrm{~b}$ & $80,95 \mathrm{a}$ & $20,32 \mathrm{c}$ & $94,66 \mathrm{a}$ & $21,86 \mathrm{~b}$ & $0,37 \mathrm{~b}$ & $59,90 \mathrm{a}$ & $4,81 \mathrm{a}$ & $75,65 \mathrm{a}$ \\
BRS Platina & $3,15 \mathrm{a}$ & $12,77 \mathrm{a}$ & $81,15 \mathrm{a}$ & $22,27 \mathrm{~b}$ & $94,02 \mathrm{a}$ & $23,11 \mathrm{~b}$ & $0,65 \mathrm{a}$ & $36,72 \mathrm{~b}$ & $4,27 \mathrm{~b}$ & $75,15 \mathrm{a}$ \\
BRS Preciosa & $2,96 \mathrm{a}$ & $12,74 \mathrm{a}$ & $82,02 \mathrm{a}$ & $22,91 \mathrm{~b}$ & $93,91 \mathrm{a}$ & $25,94 \mathrm{a}$ & $0,93 \mathrm{a}$ & $28,78 \mathrm{~b}$ & $4,31 \mathrm{~b}$ & $70,68 \mathrm{c}$ \\
BRS Princesa & $3,18 \mathrm{a}$ & $10,00 \mathrm{~b}$ & $84,20 \mathrm{a}$ & $19,92 \mathrm{c}$ & $95,74 \mathrm{a}$ & $26,88 \mathrm{a}$ & $0,74 \mathrm{a}$ & $37,87 \mathrm{~b}$ & $4,16 \mathrm{~b}$ & $69,20 \mathrm{c}$ \\
\hline BRS Vitória & $3,18 \mathrm{a}$ & $14,10 \mathrm{a}$ & $81,89 \mathrm{a}$ & $21,82 \mathrm{~b}$ & $93,22 \mathrm{a}$ & $23,68 \mathrm{~b}$ & $0,81 \mathrm{a}$ & $29,50 \mathrm{~b}$ & $4,21 \mathrm{~b}$ & $72,19 \mathrm{~b}$ \\
\hline Grande Naine & $2,93 \mathrm{a}$ & $13,55 \mathrm{a}$ & $77,40 \mathrm{~b}$ & $32,73 \mathrm{a}$ & $88,87 \mathrm{~b}$ & $22,28 \mathrm{~b}$ & $0,40 \mathrm{~b}$ & $56,38 \mathrm{a}$ & $5,00 \mathrm{a}$ & $77,22 \mathrm{a}$ \\
\hline Prata Anã & $2,86 \mathrm{a}$ & $11,22 \mathrm{~b}$ & $83,53 \mathrm{a}$ & $23,46 \mathrm{~b}$ & $94,98 \mathrm{a}$ & $26,94 \mathrm{a}$ & $0,71 \mathrm{a}$ & $38,43 \mathrm{~b}$ & $4,19 \mathrm{~b}$ & $69,94 \mathrm{c}$ \\
\hline Média & 3,05 & $12,17^{*}$ & $70,15^{*}$ & $23,35^{*}$ & $93,63^{*}$ & $24,38^{*}$ & $0,66^{*}$ & $41,08^{*}$ & $4,42^{*}$ & $72,86^{*}$ \\
\hline CV (\%) & 8,10 & 5,96 & 2,39 & 6,97 & 1,04 & 4,82 & 19,70 & 16,76 & 4,20 & 1,43 \\
\hline
\end{tabular}

DF - diâmetro do fruto em cm; CF - comprimento do fruto em cm; $\mathrm{L}^{\prime}$ - luminosidade; $\mathrm{C}^{*}$ - (croma/saturação da cor) e $\mathrm{h}^{*}$ (tonalidade/ângulo de cor); SS - sólidos solúveis ('Brix); AT - acidez titulável em \% de ácido málico. Médias ( $\mathrm{n}=3$ ) seguidas de mesma letra na coluna pertencem ao mesmo grupo pelo teste de Scott-Knott a 5\% de significância.

\section{TABELA 3. MÉDIAS DAS CARACTERÍSTICAS FÍSICAS E FÍSICO-QUÍMICAS DE BANANAS-PASSA PRODUZIDAS COM FRUTOS DIFERENTES VARIEDADES DE BANANEIRA. CRUZ DAS ALMAS, BA, 2014.}

\begin{tabular}{llllllllllll}
\hline Variedade & DF & CF & L $^{*}$ & $\mathrm{C}^{*}$ & $\mathrm{~h}^{*}$ & SS & AT & SS/AT & pH & Umidade & Rend \\
\hline BRS Caipira & $1,61 a$ & $8,77 b$ & $47,80 a$ & $20,69 b$ & $57,49 a$ & $72,86 a$ & $1,47 a$ & $50,03 a$ & $5,39 a$ & $15,75 b$ & $13,93 b$ \\
BRS Platina & $1,55 a$ & $11,05 a$ & $42,85 a$ & $21,16 b$ & $55,10 a$ & $72,92 a$ & $1,87 a$ & $39,18 a$ & $4,79 a$ & $23,25 a$ & $14,70 b$ \\
BRS Preciosa & $1,63 a$ & $12,15 a$ & $46,66 a$ & $30,08 a$ & $59,63 a$ & $73,31 a$ & $1,93 a$ & $38,90 a$ & $4,79 a$ & $20,45 a$ & $16,63 b$ \\
BRS Princesa & $1,80 a$ & $8,57 b$ & $44,54 a$ & $21,60 b$ & $50,99 a$ & $70,62 a$ & $1,56 a$ & $46,99 a$ & $4,62 a$ & $21,25 a$ & $23,28 a$ \\
BRS Vitória & $1,73 a$ & $13,07 a$ & $46,93 a$ & $23,27 b$ & $55,92 a$ & $64,16 a$ & $2,21 a$ & $29,41 a$ & $4,47 a$ & $21,47 a$ & $16,75 b$ \\
\hline Grande Naine & $1,34 a$ & $11,18 a$ & $32,32 b$ & $15,86 b$ & $39,66 a$ & $74,61 a$ & $1,62 a$ & $47,00 a$ & $5,22 a$ & $23,68 a$ & $12,89 b$ \\
Prata Ana & $1,34 a$ & $9,03 b$ & $51,67 a$ & $38,58 a$ & $71,86 a$ & $72,77 a$ & $1,58 a$ & $48,83 a$ & $4,63 a$ & $20,41 a$ & $18,34 b$ \\
\hline Média & 1,570 & $10,54^{*}$ & $44,68^{*}$ & $24,46^{*}$ & 55,81 & 71,61 & 1,75 & 42,91 & 8,19 & $20,89^{*}$ & $16,64^{*}$ \\
\hline CV (\%) & 16,48 & 9,79 & 8,56 & 29,19 & 19,52 & 12,94 & 16,82 & 27,11 & 4,05 & 10,38 & 17,80
\end{tabular}

DF - diâmetro do fruto em cm; CF - comprimento do fruto em cm; $L$ ' luminosidade; $a^{*}$ intensidade de verde/vermelho; $b^{*}$ intensidade de azul/amarelo; $\mathrm{C}^{*}$ (croma/saturação da cor) e $\mathrm{h}^{*}$ (tonalidade/ângulo de cor); $\mathrm{SS}$ - sólidos solúveis ( ${ }^{\circ}$ Brix); AT - acidez titulável em \% de ácido málico; Rend rendimento; TS tempo de secagem em horas. Médias $(n=3)$ seguidas de mesma letra na coluna pertencem ao mesmo grupo pelo teste de Scott-Knott a 5\% de significância.

No geral, a análise da cor mostrou que o processo de desidratação contribuiu para a obtenção de um produto de coloração mais escura e de tonalidade amarelo alaranjada em relação aos frutos in natura, conforme os menores valores de $\mathrm{L}^{*} \mathrm{e} \mathrm{h}^{*}$ observados no produto (Tabelas 2 e 3 ). 
As bananas-passa das variedades Prata Anã $\left(C^{*}=38,58\right)$ e BRS Preciosa $\left(C^{*}=30,08\right)$ apresentaram coloração mais intensa do que as demais (Tabela 2). A cor é um dos atributos de qualidade que influencia diretamente a aceitação de um produto. $O$ escurecimento das bananas durante a secagem tem sido associado com a ocorrência da reação de caramelização e da reação de Maillard (Leite et al. 2007) e é potencializado pelo aumento da temperatura e pela redução da umidade (Baini \& Langrish 2009).

As variedades Prata Anã, BRS Preciosa e BRS Princesa in natura formaram um grupo e destacaram-se por apresentar os maiores teores SS (Tabela 2). Entretanto, após a desidratação, todas as variedades ficaram no mesmo grupo (Tabela 3). A perda de água durante a desidratação levou à concentração dos açúcares, com aumento do teor de sólidos solúveis de $24,38^{\circ}$ Brix para $71,61^{\circ} \mathrm{Brix}$ (valores médios). Batista et al. (2014) encontraram valor inferior ao obtidos no presente estudo para banana-passa de Prata Anã $\left(57,6^{\circ} \mathrm{Brix}\right)$ e valor semelhante para banana-passa de BRS Caipira ( $\left.72,42^{\circ} \mathrm{Brix}\right)$. Entretanto nos estudos de Jesus et al. ( 2005) e Mota (2005), os valores de SS obtidos foram menores. Jesus et al. (2005) encontraram variação de 58,9Brix (Prata Graúda) a $67,6^{\circ}$ Brix (Prata Anã) em bananas-passa elaboradas com oito variedades e Mota (2005) obteve variação de $66,72^{\circ}$ Brix a $67,63^{\circ}$ Brix bananas-passa elaboradas com seis variedades. As umidades das bananas-passas nos três estudos supracitados foi de no máximo $25 \%$.

Os frutos das variedades com maiores valores de acidez titulável e menores valores de $\mathrm{pH}$ apresentaram os menores valores de relação SS/AT, ou seja, menor doçura (Tabela 2). Após a desidratação, as sete variedades formaram um único grupo considerando os teores de SS, AT, pH e relação SS/AT (Tabela 3). A relação SS/AT representa o balanço entre os açúcares e os ácidos dos frutos e contribui diretamente para a formação do sabor dos frutos e dos produtos processados. Assim, frutos com maiores valores de SS/AT apresentam doçura mais pronunciada e menor acidez e, geralmente, são preferidos pelos consumidores. Batista et al. (2014) avaliaram bananas-passa elaboradas com frutos de variedades de bananeira produzidas em cultivo orgânico e obtiveram valores de SS/AT diferentes dos obtidos no presente estudo, sendo 68,97 para BRS Caipira e 35,81 para Prata Anã. Mota (2005) obtiveram valores de acidez titulável para bananas-passa elaboradas com oito variedades de banana entre 1,37\% (Nanica) e 2,15\% de ácido málico (Marmelo).

Três variedades (BRS Caipira, Grande Naine e BRS Platina) apresentaram os maiores valores de umidade quando in natura, mas após a desidratação, observou-se que a variedade BRS Caipira apresentou o menor valor (15,75\%) (Tabela 3). É importante destacar que todas as variedades apresentaram teor de umidade inferior a $24 \%$, o que é desejável para a conservação do produto, haja vista que bananas-passa com teores de umidade superiores a $25 \%$ apresentam menor vida de prateleira devido à ocorrência de reações químicas e desenvolvimento de microorganismos. Jesus et al. (2005) também encontraram teores de umidade inferiores a $25 \%$, com variação de 18 \% (Prata Graúda) a 21,2\% (Pacovan) enquanto Mota (2005) obtiveram valores entre $21,45 \%$ (Ouro) e $25,29 \%$ (Marmelo).

Quanto ao rendimento das passas, a variedade BRS Princesa destacou-se com 23,28\% (Tabela 3). Observou-se que as variedades com frutos maiores (Tabela 2) não proporcionaram os maiores rendimentos do processo (Tabela 3 ). Diversos fatores podem interferir no rendimento do produto como peso e umidade dos frutos in natura, espessura da casca, umidade final do produto e tempo de secagem. O tempo médio de secagem das variedades foi de 26,13 horas (Tabela 3).

Avaliação sensorial

As bananas-passa produzidas com as variedades BRS Platina, BRS Preciosa, Grande Naine e Prata Anã ficaram no mesmo grupo para a aparência $(p>0,05)$ e foram consideradas melhores para esse atributo (Tabela 4). Ao considerar o percentual de aceitação, observa-se que o número de pessoas que atribuíram notas superiores a seis, foi maior para as variedades BRS Platina e Grande Naine, o que demonstra que a variedade melhorada supracitada apresentou aos consumidores impressão visual tão satisfatória quanto à variedade 'Grande Naine', já utilizada pela maioria das agroindústrias para produção de banana-passa. As passas produzidas com a variedade BRS Vitória 
foram menos aceitas para esse atributo. Observa-se assim que a apresentação dos percentuais de aceitação dos atributos sensoriais complementam os resultados do teste de média, pois os cálculos levam em consideração apenas o número de consumidores que realmente gostaram das amostras, ou seja, que atribuíram notas iguais ou maiores do que seis.

\section{TABELA 4- VALORES MÉDIOS DOS ATRIBUTOS SENSORIAIS, DA APROVAÇÃO E DA INTENÇÃO DE COMPRA DE BANANAS-PASSA PRODUZIDAS COM DIFERENTES VARIEDADES DE BANANEIRA. CRUZ DAS ALMAS, 2015.}

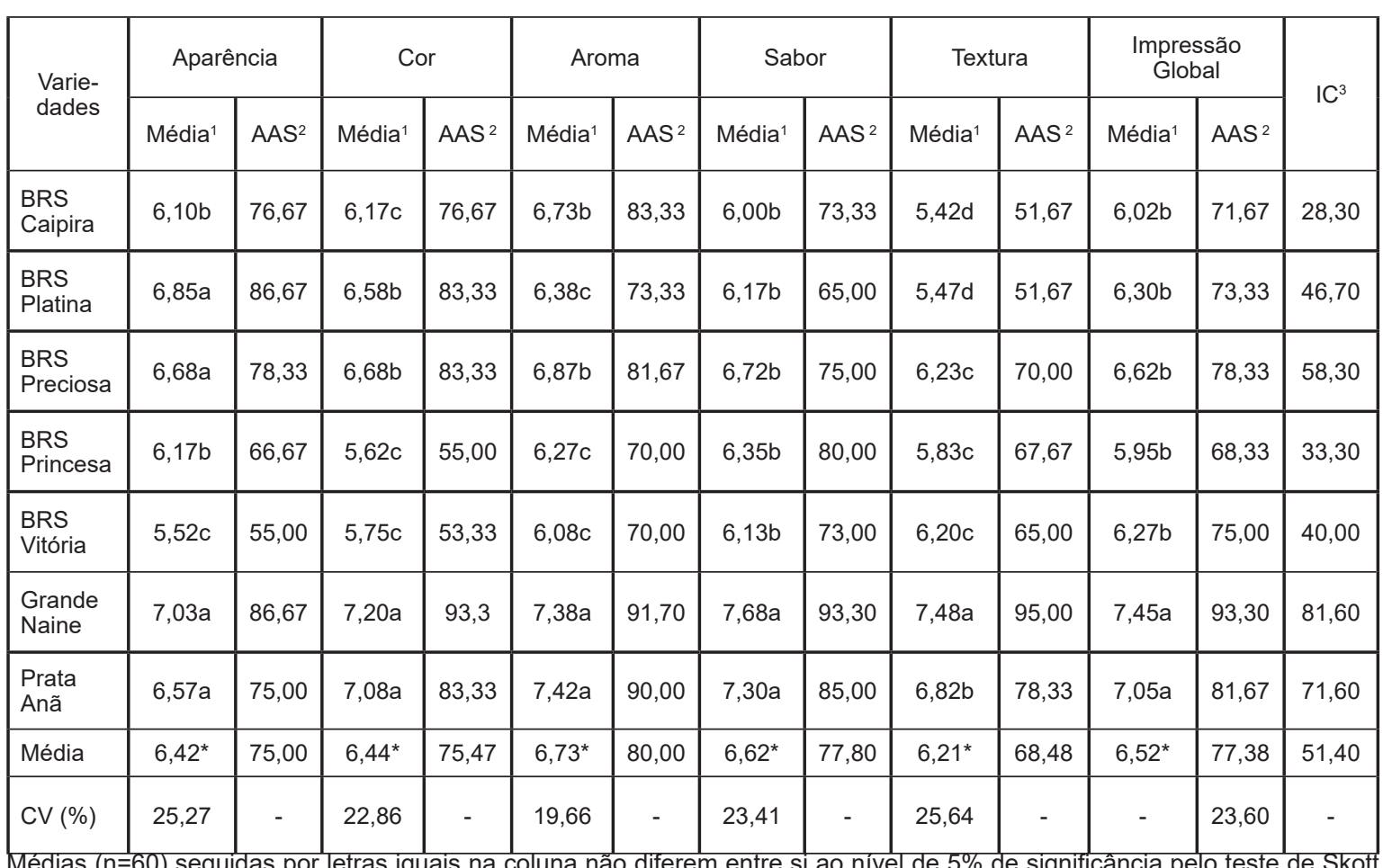

Knott. "significativo a $5 \%$ de probabilidade pelo teste $\mathrm{F}$; ${ }^{\text {n.s. }}$ não significativo a $5 \%$ de probabilidade pelo teste $\mathrm{F}$.

(1)média das notas hedônicas $(x=60)$ segundo escala de nove pontos, com os termos "desgostei muitíssimo" (1) e "gostei muitíssimo" (9) nos extremos da escala.

(2)AAS: aprovação do atributo sensorial, sendo o resultado expresso em porcentagem de notas $\geq 6$.

(3)IC: porcentagem de intenção de compra.

Para os atributos cor, aroma, sabor e impressão global, as bananas-passa produzidas com as variedades Grande Naine e Prata Anã ficaram no mesmo grupo, portanto, não apresentaram diferença significativa entre si $(p>0,05)$ e receberam notas superiores a sete, sendo classificadas entre os termos hedônicos "gostei moderadamente" e "gostei muito". Essas variedades apresentaram ainda os maiores percentuais de aceitação para os atributos supracitados (Tabela 4). No estudo conduzido por Dourado et al. (2012) as bananas-passa elaboradas com a variedade Prata também apresentaram elevada aceitabilidade (notas superiores a 7), sendo o sabor, o atributo de qualidade mais apreciado.

Considerando os percentuais de aprovação dos atributos cor e aroma observa-se que, entre as variedades melhoradas, as variedades BRS Platina e BRS Preciosa, apresentaram os maiores índices, com valores de 83,33\% para cor e acima de $73 \%$ para aroma (Tabela 4).

As passas elaboradas com as variedades melhoradas BRS Caipira e BRS Platina apresentaram os menores índices de aprovação pelos consumidores para o atributo textura $(51,67$ \%) (Tabela 4).

Jesus et al. (2005) avaliaram frutos de diferentes genótipos de bananeira e obtiveram notas semelhantes ao do presente estudo para Prata Anã, sendo 6,9 para os atributos aceitação 
global, aparência e cor; nota 7,1 para aroma; nota 7,2 para sabor e nota 6,4 para textura. Para a variedade BRS Caipira, as notas variaram de 6 a 6,4, sendo, 6,2 para aceitação global e cor; 6,4 para aparência; 6,3 para aroma e sabor e 6,0 para textura.

Ao considerar a impressão global, verificou-se que as bananas-passa produzidas com as variedades comerciais Grande Naine e Prata Anã ficaram no mesmo grupo e foram as mais aceitas pelos consumidores, além de apresentarem índices de aprovação acima de 80\% (Tabela 4). A impressão global é um atributo importante, pois expressa a percepção do consumidor em relação a todos os atributos sensoriais avaliados. Com base nesse atributo, observou-se que a maioria dos consumidores aprovou o uso das variedades melhoradas para a produção de passas, pois a aprovação foi superior a $68 \%$, com destaque para a variedade BRS Preciosa, que apresentou percentual de $78,33 \%$.

Quanto à intenção de compra pelos consumidores, observa-se que as variedades comerciais Grande Naine e Prata Anã apresentaram os maiores percentuais, sendo 81,60 e 71,60\%, respectivamente. Considerando as variedades melhoradas, os consumidores demonstraram maior intenção de compra pelas variedades BRS Preciosa e BRS Platina, com percentuais de 58,30 e $46,70 \%$, respectivamente (Tabela 4).

AFigura 1 apresenta o diagnóstico de atributos para cada atributo avaliado. Pode-se observar que as bananas-passa produzidas com as variedades Prata Anã e BRS Preciosa apresentaram perfis sensoriais semelhantes e intensidade intermediária dos atributos cor, aroma, sabor de banana e doçura. A banana-passa elaborada com a variedade BRS Caipira apresentou maior intensidade para o atributo textura, sendo, portanto, considerada mais firme do que as demais, fato que pode estar associado à menor aceitação dessa variedade para esse atributo. A banana-passa produzida com a variedade Grande Naine apresentou perfil sensorial distinto das demais e maior intensidade dos atributos cor, aroma, sabor de banana e doçura. Logo, pode-se inferir que os consumidores tendem a preferir banana-passa com coloração mais escura, mais doce e com aroma e sabor mais pronunciados, já que a Grande Naine foi a variedade com maior percentual de aprovação pelos consumidores para todos os atributos avaliados.

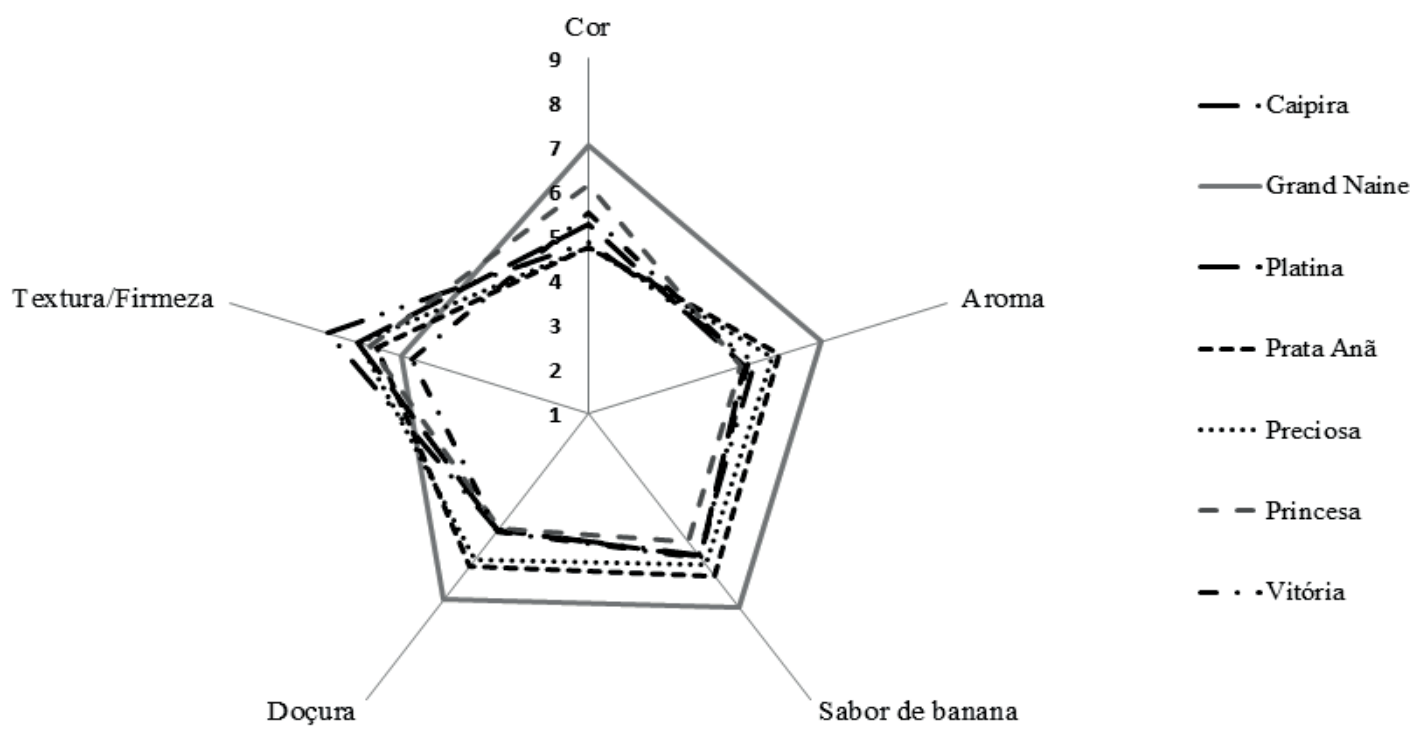

FIGURA 1. DIAGNÓSTICO DE ATRIBUTOS PARA CADA ATRIBUTO SENSORIAL AVALIADO DE BANANAS-PASSA PRODUZIDAS COM DIFERENTES VARIEDADES DE FRUTOS DE BANANEIRA. 
No geral os resultados da avaliação sensorial demonstraram que as variedades comerciais Grande Naine e Prata Anã apresentaram as maiores notas e percentuais de aprovação para cor, aroma, sabor e textura, além dos maiores percentuais de intenção de compra, provavelmente, por serem variedades que os consumidores já estão habituados a consumir. Entretanto, é importante considerar que a variedade melhorada BRS Preciosa apresentou percentual de aprovação acima de $70 \%$ e maior intenção de compra (58,30\%). Esses percentuais demonstram que essa variedade, apresenta potencial para ser adotada para a produção de passas, principalmente em locais onde o plantio das variedades comerciais tornou-se inviável devido à ocorrência de doenças. Ademais esse estudo reflete a opinião dos consumidores de uma localidade restrita e é de conhecimento que as preferências podem variar em função das diferentes regiões de consumo.

\section{CONCLUSÕES}

Os consumidores preferiram bananas-passa produzidas com as variedades comerciais 'Prata Anã' e 'Grande Naine', entretanto, os frutos das variedades melhoradas de banana são promissores para o mercado de banana-passa.

Dentre as variedades melhoradas, a 'BRS Preciosa' é a mais indicada para a produção de banana-passa por ter apresentado maior aceitação da impressão global e maior intenção de compra pelos consumidores.

\section{ABSTRACT \\ PRODUCTION OF DRIED BANANAS WITH FRUITS OF IMPROVED VARIETY AND EVALUATION OF PHYSICOCHEMICAL AND SENSORY QUALITY}

The dehidration is an interesting alternative to the use of banana, a climacteric fruit that quickly deteriorates. This study aimed to evaluate the potential of fruits of improved banana varieties for dehydration and characterize the product for their physical, physico-chemical and sensorial characteristics. Five improved varieties of banana (BRS Caipira, BRS Princesa, BRS Preciosa, BRS Platina, BRS Vitória) and two commercial cultivars (Prata Anã e Grande Naine) were used in this work. The dehydrated bananas were obtained by convective dehydration at $65^{\circ} \mathrm{C}$ until a maximum humidity of $25 \%$. The raw and the processed bananas were characterized by physical analysis (size, diameter, yield and flesh color), physico-chemical (soluble solids, titratable acidity, SS/TA, pH and humidity) and sensorial (acceptance, diagnostics of attributes and purchase intent). After dehydration, there was a reduction of $48.52 \%$ and $13.39 \%$ in the diameter and length of fruits, respectively. The dehydration process contribute to obtaining a darker product, with orange yellow hue as the lowest values of $L^{*}$ and $h$ *. The product has a dark color and orange yellow hue. There was an increase in the soluble solids content from $24,38^{\circ} \mathrm{Brix}$ in the raw bananas to $71,61^{\circ} \mathrm{Brix}$ in dehydrated product. All the varieties of bananas evaluated formed a single group considering the SS content, AT, pH and SS/TA, with humidity below $24 \%$. The improved varieties showed percentages of approval for appearance, aroma, flavor and overall impression over $65 \%$, and for color and texture more than $51 \%$. Improved varieties can be used for dehydration, highlighting the BRS Preciosa.

KEY WORDS: PROCESSING; DEHYDRATION; ACCEPTANCE; MUSA SP.; GENETIC IMPROVEMENT. 


\section{REFERÊNCIAS BIBLIOGRÁFICAS}

1 ASSOCIAÇÃO BRASILEIRA DE NORMAS TÉCNICAS (ABNT). NBR 14141: Escalas utilizadas em análise sensorial de alimentos e bebidas. Rio de Janeiro, 1998.

2 AMORIM, E. P.; SILVA, S. O.; AMORIM, V. B.; PILLAY, M. Quality improvement of cultivated Musa. In: PILLAY, M.; TENKOUANO, A. (Org.). Banana breeding: progress and challenges. New York: CRC Press, 2011. p. 252-280.

3 AZOUBEL, P.M.; BAIMA, M. A. O.; AMORIM, M. R.; OLIVEIRA, S. S. B. Effect of ultrasound on banana cv Pacovan drying kinetics. Journal of Food Engineering, Oxford, v. 97, p. 194-198, mar. 2010.

4 BAINI, R.; LANGRISH, T.A.G. Assessment of colour development in dried bananas - measurements and implications for modelling. Journal of Food Engineering, v. 93 p. 177-182, jul. 2009.

5 BATISTA, D. V.; CARDOSO, R. L.; GODOY, R. C. B.; EVANGELISTA-BARRETO, N. S. Estabilidade físico-química e microbiológica de banana-passa orgânica. Ciência Rural, v.44, n.10, p.1886-1892, out. 2014.

6 CANO-CHAUCA, M.; RAMOS, A. M.; STRINGHETA, P. C.; MARQUES, J. A.; SILVA, P. I. Curvas de secagem e avaliação da atividade de água da banana-passa. Boletim do Centro de Pesquisa de Processamento de Alimentos, v.22, p.121-132, jan./jun. 2004.

7 CENTRO DE QUALIDADE EM HORTICULTURA - CEAGESP. Normas para a classificação da banana. São Paulo: CEAGESP, 2006 (Documentos, 29). Disponível em: <www.ceagesp.gov.br/produtor/classific/fc_banana>. Acesso em: 20/05/2015.

8 DOURADO, K.K.; LIMA, L. C.; ROUWS, J. R. P. J. K. Avaliação da qualidade de bananas-passa cv. Prata em rodelas submetidas a diferentes temperaturas de secagem. Alimentos e Nutrição, v. 23, n. 1, p. 157-162, jan./mar. 2012.

9 FOOD AND AGRICULTURE ORGANIZATION OF THE UNITED NATIONS (FAO). FAO statistics agriculture database. 2013. Disponível em: <http://www.fao.org>. Acesso em: 23 mar. 2015.

10 FERREIRA, D. F. Sisvar: sistema de análise de variância. Versão 5.3. Lavras, Minas Gerais: UFLA, 2010.

11 FERNANDES, F.A.N.; RODRIGUES, S.; GASPARETO, O. C. P.; OLIVEIRA, E. L. Optimization of osmotic dehydration of bananas followed by air-drying. Jornal de Engenharia de Alimentos, v.77, p. 188-193, nov. 2006.

12 INSTITUTO ADOLFO LUTZ (IAL). Métodos físico-químicos para análise de alimentos. 4. ed. Brasília-DF: Ministério da Saúde, 2008. 1018 p.

13 JESUS, S. C.; MATSUURA, F. C. A. U.; FOLEGATTI, M. I. S.; CARDOSO, R. L. Avaliação sensorial de banana-passa obtida de frutos de diferentes genótipos de bananeira. Pesquisa Agropecuária Brasileira, v. 40, n. 6, p. 573-579, jun. 2005.

14 KARIM, M. A; HAWLADER, M.N.A. Drying characteristics of banana: theoretical modelling and experimental validation. Journal of Food Engineering, v. 70, p. 35-45, set. 2005.

15 LEITE, J.B; MANCINI, M.C; BORGES, S.V. Effect of drying Temperature on the quality of dried bananas cv. Prata and d'água. LWT - Food Science and Technology, v. 40, p. 319-323, mar. 2007.

16 MEILGAARD, M.; CIVILLE, G. V.; CARR, B. T. Sensory evaluation techniques. 4. ed. Boca Raton: CRC Press, 2006. $464 \mathrm{p}$.

17 MOTA, R.V. Avaliação da qualidade de banana-passa elaborada a partir de seis cultivares. Ciência e Tecnologia de Alimentos, v. 25, n.3, p. 560-563, jul./set. 2005.

18 SILVA, S.O.; GASPAROTTO, L.; MATOS, A. P.; CORDEIRO, Z., J., M.; FERREIRA, C. F.; RAMOS, M. M.; JESUS, O. N. Programa de melhoramento de bananeira no Brasil: resultados recentes. Cruz das Almas: Embrapa Mandioca e Fruticultura, 2003. 36 p. (Documentos, ISSN 1516-5728_n 123).

19 SILVA, C. A. B. (Coord.) Produção de banana-passa. Brasília, DF: MAARA, Secretaria do Desenvolvimento Rural, 1995. 32p. (Série Perfis Agroindustriais, 5).

\section{AGRADECIMENTOS}

Ao Dr. Edson Perito Amorim, melhorista da cultura da bananeira pela indicação das variedades e disponibilização dos frutos para essa pesquisa. À Embrapa pelo apoio financeiro e à concessão das bolsas. 